EGU2020-4197, updated on 11 May 2020

https://doi.org/10.5194/egusphere-egu2020-4197

EGU General Assembly 2020

(c) Author(s) 2020. This work is distributed under

the Creative Commons Attribution 4.0 License.

\title{
Development of a method to identify alpha-emitter-bearing- particles in soil samples collected in the Fukushima Dai-ichi Nuclear Power Plant (FDNPP) area
}

\author{
Aurélie Diacre ${ }^{1}$, Anne-Lare Faure ${ }^{1}$, Agnès Moureau ${ }^{2}$, Olivier Marie ${ }^{1}$, Nina Griffiths ${ }^{2}$, Olivier Evrard ${ }^{3}$, \\ and Fabien Pointurier ${ }^{1}$ \\ ${ }^{1}$ Commissariat à l'Energie Atomique et aux énergies renouvelables (CEA, DAM, DIF), F-91297 Arpajon, France \\ ${ }^{2}$ Laboratoire de Radio Toxicologie, CEA, Université Paris-Saclay, 91297 Bruyères[le[Châtel, France \\ ${ }^{3}$ Laboratoire des Sciences du Climat et de l'Environnement (LSCE/IPSL), Unité Mixte de Recherche 8212 (CEA/ CNRS/UVSQ), \\ Université Paris-Saclay, Gif-sur-Yvette, France
}

The Fukushima Dai-ichi Nuclear Power Plant (FDNPP) accident that occurred in March 2011 released significant quantities of radionuclides in the environment. So far, most of the research focused on radio-cesium and rarely on actinides. Until now, most of the studies on uranium and plutonium released by FDNPP were conducted on bulk environmental samples (soil, sediment, biota, etc.) and rarely on individual particles The investigation of individual particles allows working on the FDNPP signature alone compared to studies of bulk material which may also incorporate the signature of global fallout. Accordingly, the objective of the current research is to identify and characterize actinide-bearing particles in soil samples collected in the vicinity of FDNPP to get a better understanding of their formation mechanisms and of their fate in the environment. In order to identify and locate actinide-bearing particles in soil samples, we developed and implemented a method based on alpha-autoradiography (Jaegler et al., 2019), which allows identifying and locating specifically alpha-emitters, including plutonium isotopes $239 \mathrm{Pu}, 240 \mathrm{Pu}$ and $241 \mathrm{Pu}$ using a CR39 SSNTD device (Solid State Nuclear Tracks Detector).

Before alpha-autoradiography samples were dried, grinded with an agate mortar and sieved to several cutoffs: $1 \mathrm{~mm}, 700 \mu \mathrm{m}, 400 \mu \mathrm{m}, 200 \mu \mathrm{m}, 100 \mu \mathrm{m}$ and $63 \mu \mathrm{m}$. Cutoffs were chosen according to the sizes of actinide-bearing particles detected by Satou et al (2018). The absence of significant loss of uranium particles by the sieving process was demonstrated by the analysis of a test soil sample with a ${ }^{137} \mathrm{Cs}$ activity below $650 \mathrm{~Bq} / \mathrm{kg}$ spiked with depleted uranium reference particles. After sieving, the test sample was deposited onto a carbon planchet for secondary ion mass spectrometry analysis in order to determine the particle recovery yield.

Then, the detection of actinide-bearing particles by means of alpha autoradiography was performed on various soil samples collected in the vicinity of FDNPP. Longer exposure times logically improve the detection efficiency of alpha-emitters-bearing particles. However, the exposure time should not exceed two months to limit the impact of emissions from naturallyoccurring alpha-emitters. 
We will present here the first results of detection of alpha-emitting particles in the analyzed soil samples. Relative impacts of naturally-occurring alpha-emitters $\left({ }^{234} \mathrm{U} /{ }^{238} \mathrm{U},{ }^{235} \mathrm{U},{ }^{232} \mathrm{Th}\right.$ and daughter nuclides) and of plutonium isotopes on alpha-radiography trace observation will be discussed.

The next steps of this study will be to develop and implement methods to sample and isolate alpha-emitting particles from the soil matrix and to characterize them in size, morphology, elemental and isotopic compositions. Full characterization of individual particles will be very helpful to determine their origin and to provide an understanding of their formation process and to determine their mobility and life-duration in the environment.

\section{References:}

- H. Jaegler, F. Pointurier, et al., 2019. Method for detecting and characterising actinide-bearing micro-particles in soils and sediment of the Fukushima Prefecture, Japan. Journal of Radioanalytical and Nuclear Chemistry, 321 (2019), 57-69. doi:10.1007/s10967-019-06575-w

- Y. Satou, K. Sueki,et al., 2018. Analysis of two forms of radioactive particles emitted during the early stages of the Fukushima Dai-ichi Nuclear Power Station accident. Geochemical Journal, 52 (2018), 1-7. doi:10.2343/geochemj.2.0514. 